\title{
Fever of unknown origin due to primary tubercular splenic abscess in a low-income/middle-income
} country

\author{
Jasmine Sethi, ${ }^{1}$ Abhinav Shrivastava, ${ }^{2}$ Krishan Lal Gupta ${ }^{1}$
}

\begin{abstract}
${ }^{1}$ Nephrology, Postgraduate Institute of Medical Education and Research, Chandigarh, Punjab, India

${ }^{2}$ Internal Medicine, Postgraduate Institute of Medical Education and Research, Chandigarh, Punjab, India
\end{abstract}

Correspondence to Professor Krishan Lal Gupta, klgupta@hotmail.com

Accepted 1 August 2018

\section{DESCRIPTION}

A 49-year-old non-diabetic woman was admitted to our hospital with complaints of fever of unknown origin (FUO) of 2 months' duration. The patient has no recent history of exposure to tuberculosis (TB). Systemic examination revealed pallor and tender splenomegaly. Blood investigations revealed a microcytic hypochromic anaemia with haemoglobin of $7.5 \mathrm{~g} / \mathrm{dL}$, total leucocyte count of $12.7 \times 10 \wedge 9 / \mathrm{L}$ and a raised erythrocyte sedimentation rate (ESR) $(62 \mathrm{~mm} /$ hour). The rest of the FUO work-up, including blood cultures, serologies, chest radiograph, Mantoux and echocardiography, was unremarkable. Contrast-enhanced CT of the abdomen revealed multiple splenic abscesses (figure 1), from which a diagnostic and therapeutic single time aspiration was done. Around $10 \mathrm{~mL}$ of pus was aspirated which showed smear positivity for Mycobacterium tuberculosis (figure 2). The patient was subsequently started on four-drug antitubercular treatment. The fever subsided and repeat serial ultrasound imaging showed resolution of splenic abscess. Primary splenic TB in an immunocompetent patient is a rare entity but should be considered as a diagnostic possibility especially in a country where TB is endemic.

Splenic abscess has a very low incidence $(0.1 \%-$ $0.7 \%$ on autopsy) and tubercular splenic abscess is even rarer. ${ }^{1}$ Usually spleen is involved in disseminated $\mathrm{TB}$, and primary splenic $\mathrm{TB}$ is extremely uncommon with only few cases published in the literature. ${ }^{1-4}$ Splenic abscess is mostly seen in patients with underlying immunocompromised

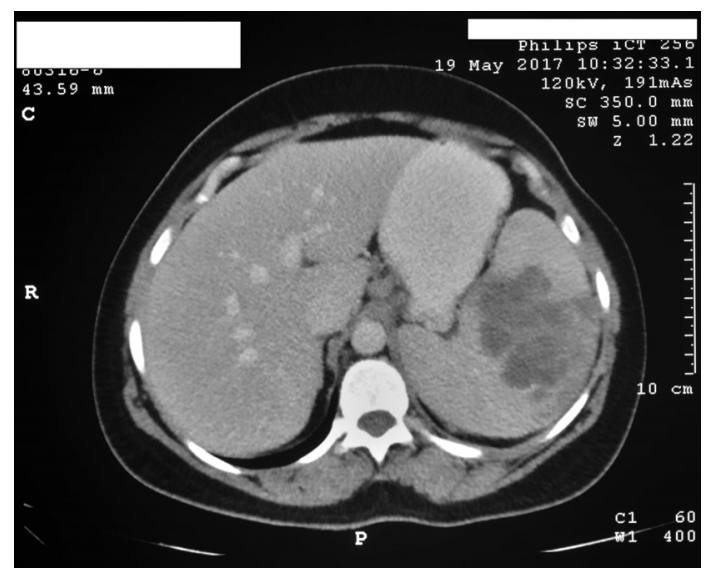

Figure 1 CT scan of the abdomen showing multiple conglomerating hypodense lesions in the splenic parenchyma suggestive of abscesses.

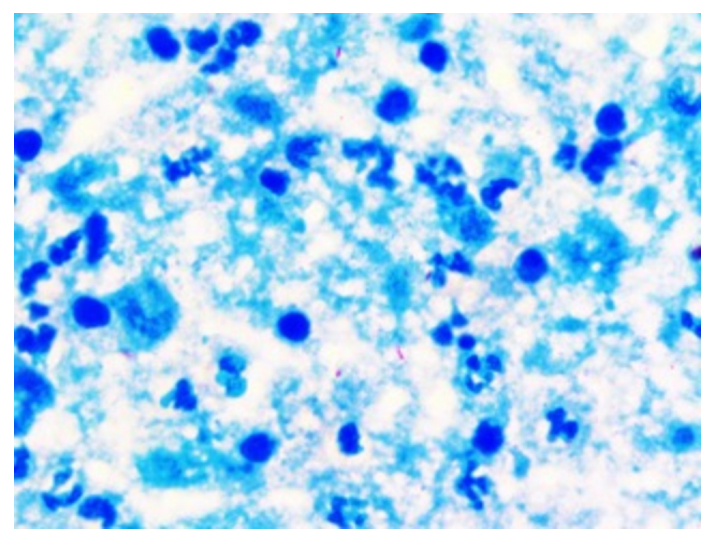

Figure 2 Smear from pus aspirated from splenic abscess showing degenerated neutrophils, macrophages in a background of necrosis and stained positive for acidfast bacilli.

state, which includes diabetes, transplant recipients, intravenous drug abuse and retropositivity. ${ }^{1}$ It is most commonly caused by Gram-negative organisms, with Klebsiella as the most commonly isolated organism. ${ }^{5}$ CT differentials of the splenic abscess include splenic lymphoma, metastasis, parasitic cyst, infarction, haemangioma, sarcoidosis and trauma. Differentiating tubercular from pyogenic splenic abscess on CT can sometimes be difficult; however, unilocular abscess, rim enhancement and gas formation within the lesion favour pyogenic abscess. ${ }^{6}$ Treatment consists of antitubercular therapy and spleen-saving surgery such as percutaneous single time aspiration. The above case is presented because of the rarity of occurrence of primary splenic $\mathrm{TB}$ and its successful management with single time splenic aspiration and antitubercular drugs.

\section{Learning points}

Splenic tuberculosis should be considered in patients with fever of unknown origin and splenomegaly especially in our country where tuberculosis is endemic.

- Ultrasonography of the abdomen can be a useful and cost-effective mode to suspect this rare entity.

Contributors JS and AS: writing, concept, image acquisition. KLG: proof-reading, corrections. 
Funding The authors have not declared a specific grant for this research from any funding agency in the public, commercial or not-for-profit sectors.

Competing interests None declared.

Patient consent Obtained

Provenance and peer review Not commissioned; externally peer reviewed.

\section{REFERENCES}

1 Agarwala S, Bhatnagar V, Mitra DK, et al. Primary tubercular abscess of the spleen. J Pediatr Surg 1992;27:1580-1.
2 Kumar S, Pai AG, Tungenwar PN, et al. Isolated primary tuberculosis of spleen-A rare entity in the immuno-competent patient. Int I Surg Case Rep 2017;30:93-6.

3 Hamizah R, Rohana AG, Anwar SA, et al. Splenic tuberculosis presenting as pyrexia of unknown origin. Med I Malaysia 2007:62:70-1.

4 Neki NS, Batra KS, Sharma RK, et al. Isolated tubercular splenic abscess. J Assoc Physicians India 2001:49:759-60.

5 Chang KC, Chuah SK, Changchien CS, et al. Clinical characteristics and prognostic factors of splenic abscess: a review of 67 cases in a single medical center of Taiwan. World I Gastroenterol 2006;12:460-4.

6 Karlo CA, Stolzmann P, Do RK, et al. Computed tomography of the spleen: how to interpret the hypodense lesion. Insights Imaging 2013;4:65-76.

Copyright 2018 BMJ Publishing Group. All rights reserved. For permission to reuse any of this content visit

http://group.bmj.com/group/rights-licensing/permissions.

BMJ Case Report Fellows may re-use this article for personal use and teaching without any further permission.

Become a Fellow of BMJ Case Reports today and you can:

- Submit as many cases as you like

- Enjoy fast sympathetic peer review and rapid publication of accepted articles

Access all the published articles

Re-use any of the published material for personal use and teaching without further permission

For information on Institutional Fellowships contact consortiasales@bmjgroup.com

Visit casereports.bmj.com for more articles like this and to become a Fellow 